\title{
Fluorine-vacancy complexes in ultrashallow B-implanted Si
}

\author{
D. A. Abdulmalik and P. G. Coleman ${ }^{\text {a) }}$ \\ Department of Physics, University of Bath, Bath BA2 7AY, United Kingdom \\ N. E. B. Cowern, A. J. Smith, and B. J. Sealy \\ Advanced Technology Institute, University of Surrey, Guildford, Surrey GU2 7XH, United Kingdom \\ W. Lerch and S. Paul \\ Mattson Thermal Products GmbH, Daimlerstr. 10, D-89160 Dornstadt, Germany \\ F. Cristiano \\ LAAS-CNRS, 7 Avenue du Colonel Roche, 31077 Toulouse Cedex 4, France
}

(Received 11 May 2006; accepted 21 June 2006; published online 3 August 2006)

\begin{abstract}
Shallow fluorine-vacancy (FV) complexes in Si have been directly observed using variable-energy positron annihilation spectroscopy and secondary ion mass spectrometry. The FV complexes, introduced to combat the deactivation and transient-enhanced diffusion of ultrashallow boron, were observed in preamorphized Si wafers implanted with $0.5 \mathrm{keV} \mathrm{B}$ and $10 \mathrm{keV} \mathrm{F}$ ions at a dose of $10^{15} \mathrm{~cm}^{-2}$, and then annealed isothermally at $800{ }^{\circ} \mathrm{C}$ for times ranging from 1 to $2700 \mathrm{~s}$. The results are in agreement with a model which predicts that the complexes are of the form $\mathrm{F}_{3 n} V_{n}$, with $n$ most probably being 1 and/or 2. (C) 2006 American Institute of Physics. [DOI: 10.1063/1.2335594]
\end{abstract}

Interest in the beneficial consequences of implanting $\mathrm{F}$ ions in $\mathrm{Si}$ has grown in recent years as defect engineering has been developed to meet the continuing challenges of device miniaturization. The application of particular interest here concerns ultrashallow B implantation into preamorphized $\mathrm{Si}$ regrown via solid-phase epitaxy (SPE); efficient activation of the B while limiting its diffusion is the key to the formation of ultrashallow junctions. Recent work by Cowern et al. ${ }^{1}$ showed that $\mathrm{F}$ in $\mathrm{B}$-implanted $\mathrm{Si}$ can form clusters that trap interstitals $(I)$ released from the band of end-of-range (EOR) defects, which in turn both retard the transient enhanced diffusion of B implants and significantly decrease their deactivation. Kham et al. ${ }^{2}$ linked $\mathrm{F}$ found at half the projected ion range to the formation of clusters of $\mathrm{F}$ with vacancies $(V)$ in this region. Other studies conclude that FV or FI complexes suppress B diffusion by reducing $I$ emission from extended $I$ defects generated by implantation. 3,4

Variable-energy positron annihilation spectroscopy (VEPAS) is used here to probe the nature of the complexes formed by the implanted $\mathrm{F}$ ions. The technique has been used to identify FV complexes in thermally treated F-implanted $\mathrm{Si}^{5,6}$ VEPAS measures the Doppler broadening of the $511 \mathrm{keV} \gamma$-ray annihilation line, whose extent is determined by the average momentum of the electrons at the annihilation site. The broadening is characterized by the line-shape parameter $S$, defined as the central fraction of the $511 \mathrm{keV}$ line. $S$ for a chosen experimental setup has a characteristic value for each annihilation site, for example, for pure bulk Si or for each specific vacancy-type defect, the latter being strong positron traps. The mean depth $z$ of positrons implanted with energy $E(\mathrm{keV})$ is determined from the relation $z=17.2$ $E^{1.6} \mathrm{~nm}$. Secondary ion mass spectrometry (SIMS) measurements were performed to determine atomic profiles.

Samples used in this study were $n$-type $\langle 100\rangle \mathrm{Cz} \mathrm{Si}$ wafers with a resistivity of $10-20 \Omega \mathrm{cm}$. All wafers were first preamorphized with $30 \mathrm{keV}, 10^{15} \mathrm{~cm}^{-2} \mathrm{Ge}$ ions, and im-

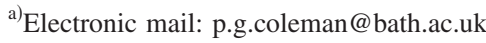

planted with $0.5 \mathrm{keV} B$ ions at $10^{15} \mathrm{~cm}^{-2}$. Half of the samples were additionally implanted with $\mathrm{F}$ ions at $10 \mathrm{keV}$ and $10^{15} \mathrm{~cm}^{-2}$, placing the $\mathrm{F}$ ions between the $\mathrm{B}$ implants and the amorphous-crystalline interface. After restoring the amorphous layer to crystallinity via SPE regrowth at $650{ }^{\circ} \mathrm{C}$, the samples were then rapidly annealed in a $\mathrm{N}_{2}$ atmosphere at $800{ }^{\circ} \mathrm{C}$ for times between 1 and $2700 \mathrm{~s}$.

Figure 1 compares the variation of the $S$ parameter, normalized to a value $\left(=S_{B}\right)$ of 1.00 for bulk $\mathrm{Si}$, with $E$ for the samples implanted with (a) B ions only and (b) B followed by $\mathrm{F}$ ions. The differences in the $S(E)$ curves for incident positron energies in the range of $\sim 5-20 \mathrm{keV}$ are due to the electric field in the depletion region. ${ }^{7}$ The solid lines in Fig. 1 are fits to the raw data using the code VEPFIT (Ref. 8) which, while being relatively insensitive to electric field, fits well the position and width of the depletion region for each sample. The model used assumed a linear electric field in the range of $(-9$ to -3.4$) \times 10^{6} \mathrm{~V} \mathrm{~m}^{-1}$ calculated as the ratio of built-in potential and depletion layer width, both related to the impurity gradient assumed for these samples. ${ }^{1}$ Because of the low doping level in the wafers used in this experiment $\left(\sim 10^{15} \mathrm{~cm}^{-3}\right)$ the fitted depletion regions extend from $\sim 150 \mathrm{~nm}$ to $300-450 \mathrm{~nm}$, for annealing times between 1 and $2700 \mathrm{~s}$, which are consistent with those expected theoretically. Under these conditions, VEPAS data are only weakly sensitive to the $\mathrm{B}$ diffusion depth. Thus, although $\mathrm{F}$ does significantly influence B diffusion, the main impact of the F implants on our VEPAS results occurs through the introduction of F-related defects.

Figure 2 highlights the most significant difference between $S(E)$ for samples with and without $\mathrm{F}$, which have both been annealed at $800{ }^{\circ} \mathrm{C}$ for $900 \mathrm{~s}$. In the sample without $\mathrm{F}$, positrons are drifted to the surface by the electric field, to be annihilated there with $S_{S} \sim 0.91 S_{B}$. In the F coimplanted samples VEPFIT analysis indicates that positrons are drifted by the field to a layer of FV complexes of $\sim 40 \mathrm{~nm}$ thickness, where they are efficiently trapped; therefore, the $S$ parameter characteristic of the defected layer $S_{D} \approx 0.87 S_{B}$ is obtained 


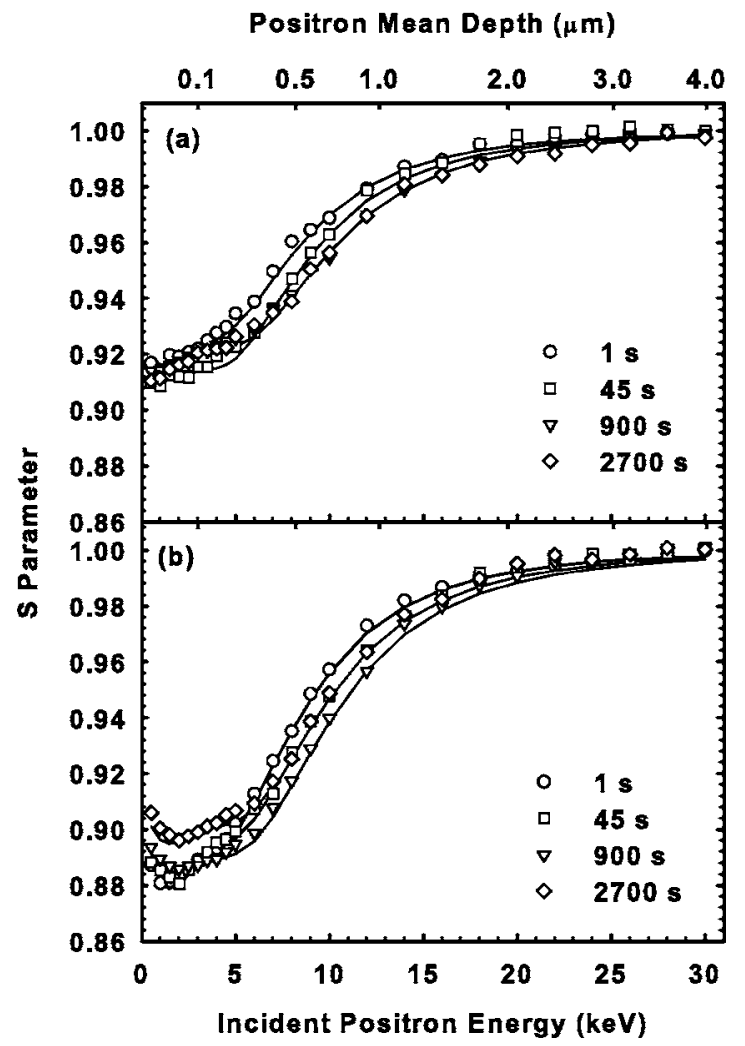

FIG. 1. (a) Normalized $S$ parameter vs incident positron energy and positron mean depth for samples implanted with $0.5 \mathrm{keV}, 10^{15} \mathrm{~cm}^{-3} \mathrm{~B}$ ions and annealed at $800{ }^{\circ} \mathrm{C}$ for different annealing times. (b) Corresponding results for a second set of samples in which $\mathrm{F}$ has been coimplanted at $10 \mathrm{keV}$ at $10^{15} \mathrm{~cm}^{-3}$. The solid lines are fits to the data obtained using VEPFIT.

via VEPFIT, rather than $S_{S}$. Low $S_{D}$ values, associated with the proximity of higher-momentum $\mathrm{F}$ electrons, were also attributed to $\mathrm{F}_{x} V_{y}$ defects by Pi et al. ${ }^{6}$ and Simpson et al. ${ }^{5}$ The slight variation in the measured near-surface $S$ in the samples without F [Fig. 1(a)] arises from the different efficiencies of the various internal electric fields in drifting the positrons to the surface. In the F-implanted samples [Fig. $1(b)]$ this small effect is overcome by the stronger effect of trapping in the defect layer with $S=S_{D}$.

At very low implantation energies some of the positrons - a fraction of which may be unthermalized-will



FIG. 2. Comparison between the $S(E)$ curves of two samples, with and without $\mathrm{F}$, annealed at $800{ }^{\circ} \mathrm{C}$ for $900 \mathrm{~s}$. without $\mathrm{F}$, annealed at $800{ }^{\circ} \mathrm{C}$ for $900 \mathrm{~s}$. $\quad \nu$, and larger if the assumption that $\nu$ for an $\mathrm{F}_{x} V_{y}$ complex is
Downloaded 30 Mar 2009 to 131.227 .178 .132 . Redistribution subject to AIP license or copyright; see http://apl.aip.org/apl/copyright.jsp



FIG. 3. SIMS profiles of $F$ in samples implanted with $0.5 \mathrm{keV}, 10^{15} \mathrm{~cm}^{-2} \mathrm{~B}$ and $10 \mathrm{keV}, 10^{15} \mathrm{~cm}^{-2} \mathrm{~F}$, and annealed at $800{ }^{\circ} \mathrm{C}$ for 15,120 , and $2700 \mathrm{~s}$.

have the ability to diffuse to the surface, evidenced by the small increase in the measured $S$ value below $\sim 1 \mathrm{keV}$; this fraction is, however, much reduced because of the electric field in the thin highly doped near-surface layer arising from band bending at the surface. ${ }^{9}$ This surface field region is so tial barrier. In the case of the samples without F, barrier penetration and reaching the surface are more likely because the positrons have longer effective diffusion lengths in the absence of the FV layer sink, and approach the barrier more often. The electric fields at the surface and across the depletion region combine to direct positrons towards the FV layer, thereby enhancing the sensitivity of VEPAS to the defected layer.

Although the FV defect concentration remains high enough to trap all the positrons that are implanted into it with energies of a few $\mathrm{keV}$ for annealing times from 1 to $900 \mathrm{~s}$, the low-energy $(E \leqslant 1 \mathrm{keV})$ shapes of $S(E)$ [see Figs. 1(b) and 2] suggest a decrease in the FV concentration with annealing time, as more positrons are able to diffuse to the surface and the increase in $S$ towards $S_{S}$ becomes more pronounced. The SIMS profiles in Fig. 3 suggest that the decrease in FV concentration is particularly marked within the first $5 \mathrm{~nm}$ or so beneath the surface.

After annealing for $2700 \mathrm{~s}$ the $S$ parameter of the defected layer increases measurably to $0.89 \mathrm{~S}_{B}$ [Fig. 1(b)]. Because the small increase in diffusion to the surface is only seen at $E<1.5 \mathrm{keV}$, VEPFIT is able unambiguously to attribute the increase in $S$ to a decrease in defect concentration. Using $S_{D}=0.87 S_{B}$, the fraction of positrons trapped in the FV defect layer after annealing for $2700 \mathrm{~s}$ is given by

$$
F=(1-0.89) /(1-0.87)=0.85 \text {. }
$$

The trapping rate $K$ of the positrons in the FV layer in the same sample is then

$$
K=\lambda_{B} F /(1-F)=2.6 \times 10^{10} \mathrm{~s}^{-1},
$$

where $\lambda_{B}$ is the positron annihilation rate in $\mathrm{Si} \quad(=4.54$ $\left.\times 10^{9} \mathrm{~s}^{-1}\right) .{ }^{10}$ Now $K=\nu C_{D}$, where $\nu$ is the specific positron trapping rate in $\mathrm{s}^{-1}\left(\approx 3 n \times 10^{14} \mathrm{~s}^{-1}\right.$, where $n$ is the number of vacancies in the defect structure ${ }^{11}$ ) and $C_{D}$ is the defect concentration per atom. Thus $C_{D}=K / \nu=(8.6 / n) \times 10^{-5}$ per atom, $\approx(4.3 / n) \times 10^{18} \mathrm{~cm}^{-3}$. The uncertainty on this value is $\sim \pm 25 \%$, mostly arising from the uncertainty in the value of thin that some positrons are still able to penetrate the poten- 
similar to that for an unattached $V_{y}$ is invalid. The SIMS profiles (Fig. 3) yield an average $\mathrm{F}$ concentration in the first $40 \mathrm{~nm}$ after annealing for $2700 \mathrm{~s}$ of $1.31 \times 10^{19} \mathrm{~cm}^{-3}$, which is $3 n$ greater than the defect concentration indicated by VEPAS. The defect structure suggested by the combination of VEPAS and SIMS is thus $\mathrm{F}_{3 n} V_{n}$, in agreement with the theoretical prediction of Diebel and Dunham ${ }^{12}$ and the experimental estimate of Cowern et al., ${ }^{1}$ from which it may be concluded that the most likely value(s) of $n$ are 1 and/or 2 .

Figure 3 also yields average $\mathrm{F}$ concentrations of (13.6 and 7.7) $\times 10^{19} \mathrm{~cm}^{-3}$ in the first $40 \mathrm{~nm}$ after annealing at $800{ }^{\circ} \mathrm{C}$ to 15 and $120 \mathrm{~s}$, respectively. These would correspond to $\mathrm{F}_{3 n} V_{n}$ concentrations of $[(4.5 / n)$ and $(2.6 / n)]$ $\times 10^{19} \mathrm{~cm}^{-3}$ and trapped fractions $F=98.5$ and $98 \%$, respectively, in line with the assumption above that at shorter annealing times essentially all the positrons annihilated in the defect layer are trapped.

The results presented in this letter provide evidence that the F-related defects introduced beneath the ultrashallow B implant are vacancy complexes $\mathrm{F}_{3 n} V_{n}$, most likely $\mathrm{F}_{3} V$ and/or $\mathrm{F}_{6} V_{2}$. The vacancies trapped by the $\mathrm{F}$ atoms are in turn able to trap the interstitials migrating from the EOR region and thus significantly reduce B diffusion, as observed by Cowern et al. ${ }^{1}$ VEPAS and SIMS results indicate that the concentration of the complexes, to within $25 \%$, decreased from $[(4.5 / n)$ to $(2.6 / n)] \times 10^{19} \mathrm{~cm}^{-3}$ between 15 and $120 \mathrm{~s}$ annealing times at $800{ }^{\circ} \mathrm{C}$, but dropped significantly to $(4.3 / n) \times 10^{18} \mathrm{~cm}^{-3}$ after annealing for $2700 \mathrm{~s}$.

The authors are grateful for the support of the EU FP6 coordination project CADRES. One of the authors (D.A.A.) thanks the state of Qatar for a government scholarship. Another author (N.E.B.C.) is sponsored by Applied Materials, Philips, and the UK Royal Academy of Engineering.

${ }^{1}$ N. E. B. Cowern, B. Colombeau, J. Benson, A. J. Smith, W. Lerch, S. Paul, T. Graf, F. Cristiano, X. Hebras, and D. Bolze, Appl. Phys. Lett. 86, 101905 (2005)

${ }^{2}$ M. N. Kham, H. A. W. El Mubarek, J. M. Bonar, and P. Ashburn, Mater. Sci. Eng., B 124/125, 192 (2005).

${ }^{3}$ H. A. W. El Mubarek, and P. Ashburn, Appl. Phys. Lett. 83, 4134 (2003).

${ }^{4}$ G. Impellizzeri, J. H. dos Santos, S. Mirabella, F. Priolo, E. Napolitani, and A. Carnera, Appl. Phys. Lett. 84, 1862 (2004).

${ }^{5}$ P. J. Simpson, Z. Jenei, P. Asoka-Kumar, R. R. Robison, and M. E. Law, Appl. Phys. Lett. 85, 1538 (2004).

${ }^{6}$ X. D. Pi, C. P. Burrows, and P. G. Coleman, Phys. Rev. Lett. 90, 155901 (2003).

${ }^{7}$ A. P. Knights and P. G. Coleman, Mater. Sci. Forum 445/446, 123 (2004).

${ }^{8}$ A. van Veen, H. Schut, J. de Vries, R. A. Hakvoort, and M. R. Ijpma, AIP Conf. Proc. 218, 171 (1990).

${ }^{9}$ J. A. Duffy, W. Bauer-Kugelmann, G. Kögel, and W. Triftshäuser, Appl. Surf. Sci. 116, 241 (1997).

${ }^{10}$ S. Dannefaer, J. Phys. C 15, 599 (1982).

${ }^{11}$ P. J. Schultz, E. Tandberg, K. G. Lynn, B. Nielsen, T. E. Jackman, M. W. Denhoff, and G. C. Aers, Phys. Rev. Lett. 61, 187 (1988).

${ }^{12}$ Milan Diebel and Scott T. Dunham, Phys. Rev. Lett. 93, 245901 (2004). 